\title{
From controlling to letting go: what are the psychosocial needs of parents of adolescents with a chronic illness?
}

\author{
Christina Akre* and Joan-Carles Suris \\ Institute of Social and Preventive Medicine (IUMSP), Lausanne University Hospital, Route de la Corniche 10, 1010 \\ Lausanne, Switzerland \\ *Correspondence to: C. Akre. E-mail: Christina.Akre@chuv.ch \\ Received on January 9, 2014; accepted on June 10, 2014
}

\begin{abstract}
While one of the main objectives of adolescence is to achieve autonomy, for the specific population of adolescents with a chronic illness (CI), the struggle for autonomy is accentuated by the limits implied by their illness. However, little is known concerning the way their parents manage and cope with their children's autonomy acquisition. Our aim was to identify the needs and preoccupations of parents of adolescents with CI in coping with their children's autonomy acquisition and to determine whether mothers and fathers coped differently. Using a qualitative approach, 30 parents of adolescents with CI participated in five focus groups. Recruitment took place in five specialized pediatric clinics from our university hospital. Thematic analysis was conducted. Transcript analyses suggested four major categories of preoccupations, those regarding autonomy acquisition, giving or taking on autonomy, shared management of treatment and child's future. Some aspects implied differences between mothers' and fathers' viewpoints and ways of experiencing this period of life. Letting go can be hard for the father, mother, adolescent or all three. Helping one or the other can in turn improve family functioning as a whole. Reported findings may help health professionals better assist parents in managing their child's acquisition of autonomy.
\end{abstract}

\section{Introduction}

Some of the main objectives of adolescence are to achieve autonomy, decrease dependency on parents and acquire greater responsibility for behavior [1]. This search for autonomy can be stressful both for adolescents and their parents [2], and the quality of their relationship plays a crucial role in the transition to autonomy [1].

Approximately $10 \%$ of adolescents suffer from a chronic illness (CI) [3, 4]. For this specific population of adolescents, the struggle for autonomy is accentuated by the limits implied by their CI, the specific treatments needed [3] and frequently overprotective parents $[5,6]$. The road to autonomy is full of obstacles as they have to take responsibility for their treatment and their medical care while longing for normality comparable to that of their peers. Moreover, when compared with their peers, adolescents with CI have a lower probability of completing their education and of being adequately oriented academically, professionally and, in the long run, economically [7].

Additionally, it is recognized that transfer of responsibility 'is not straightforward, linear or unproblematic for any of the family members (although it is often) a taken-for-granted process' [8]. For parents in particular, the management of their adolescent child's autonomy is not an easy task because they do not necessarily know what is 'normal' for their adolescent with CI and what degree of autonomy to give [9] and they often undergo tensions between 
The needs of chronically ill adolescents' parents

protection and promotion of autonomy [10]. In fact, adolescence is a crucial period for these parents: there is a higher risk of depression when anticipated independence fails to develop [11] or in the case of weak coping skills [12], and parental stress can be high [13].

Qualitative research has previously been conducted with children with $\mathrm{CI}$ and their parents examining meaning or transfer of responsibility $[8,10$, 14] and shared management [15]. However, these studies were disease-specific and mainly included children rather than adolescents. Moreover, Allan and Gregory [16] have put forward the overwhelming emphasis in the literature on how best to support young people with diabetes on fitting in with the health care system, rather than giving adolescents attention to their contemporaneous experiences and needs. In the same line, the needs of parents of adolescents with CI have also been omitted. In fact, there is practically no research concerning the way parents of adolescents with CI manage their children's autonomy acquisition, how they cope, and how they encourage or discourage it. Finally, most studies in this regard focus on mothers while fathers are largely underrepresented $[17,18]$.

The aim of our study was to fill this gap by looking at mothers and fathers of adolescents with $\mathrm{CI}$ in an attempt (i) to identify their needs and preoccupations in dealing with their children's autonomy acquisition and (ii) to determine whether mothers and fathers coped differently. This is part of an overall effort to better understand how best to meet the needs of parents of adolescents with CI at this stage of their life course.

\section{Methods}

We conducted a qualitative study using focus groups (FGs) to obtain in-depth descriptions [19] of the experience as mothers and fathers of adolescents with CI. Group interviewing is known to be an effective and efficient method as it offers the advantage of participants interacting as they query and explain themselves to each other [20]. Through consensus and diversity, discussions generate valuable data, which individuals may not articulate on their own $[21,22]$.

Thirty parents of adolescents with CI participated in 5 FGs: 18 mothers distributed in 3 FGs and 12 fathers in 2 FGs (Table I) of 20 adolescents (for 10, the mother and father participated, 8 only the mother, 2 only the father). Group size ranged from 4 to 10 participants. Segmentation by age of adolescents was done as much as possible as autonomy is experienced differently according to maturity.

We chose a non-categorical approach to CI as 'important commonalities exist in the experience of children and families affected with various kinds of conditions' [23]. We contacted five specialized pediatric clinics from our university hospital for recruitment: gastroenterology, endocrinology, neurorehabilitation, pulmonology and rheumatology. Each clinic provided a list of patients and their postal addresses according to our inclusion criteria: patient aged between 14 and 20 years; CI diagnosed for at least 1 year but not implying a mental handicap; and fluency in French. We sent out letters co-signed by the head of each clinic and research group explaining the study aim and design to parents and inviting them to contact us by e-mail or telephone if interested in taking part in a FG. Out of a total of 215 letters sent, 36 parents (22 mothers and 14 fathers) responded by e-mail or telephone and 30 finally participated. By way of appreciation, participants were given the equivalent of a US\$25 department store voucher.

The two authors moderated the FGs, one leading the discussions and the other taking notes and asking clarifying questions. Each participant signed a consent form and filled out a one-page questionnaire to describe sample's demographics (Table I). Each FG lasted $\sim 90 \mathrm{~min}$ and was audio-taped. The project was approved by the Cantonal Ethics Committee.

The authors established a discussion guide consisting of a series of open-ended questions regarding adolescents' acquisition of autonomy with particular reference to the effects of CI on family life, management of $\mathrm{CI}$ and treatments, family rules concerning children's social and school/professional life and worries about the future of the adolescent with CI. As this study used a qualitative method, we did not 
C. Akre and J.-C. Suris

Table I. FGs participants' characteristics

\begin{tabular}{|c|c|c|c|}
\hline & Parents & Child's age range & Child's CI \\
\hline FG1 & 10 mothers & $14-16$ & $\begin{array}{l}1 \text { cranial traumatism (consequences } \\
\text { of a road accident) } \\
2 \text { diabetes type } 1 \\
2 \text { ulcerative colitis } \\
1 \text { cerebrovascular accident } \\
1 \text { rheumatism } \\
2 \text { Crohn's disease } \\
1 \text { cystic fibrosis }\end{array}$ \\
\hline FG2 & 4 mothers & 17 & $\begin{array}{l}1 \text { Crohn's disease } \\
1 \text { juvenile arthritis } \\
1 \text { mild cerebral palsy } \\
1 \text { multi-disability }\end{array}$ \\
\hline FG3 & 4 mothers & $14-19$ & $\begin{array}{l}1 \text { muscular dystrophy } \\
1 \text { spinal muscular atrophy } \\
1 \text { Crohn's disease } \\
1 \text { movement disorder }\end{array}$ \\
\hline FG4 & 7 fathers & $14-17$ & $\begin{array}{l}2 \text { Crohn's disease } \\
1 \text { diabetes type } 1 \\
1 \text { hemiparesis } \\
1 \text { cranial traumatism (consequences } \\
\text { of a road accident) } \\
1 \text { rheumatism } \\
1 \text { multi-disability with epilepsy }\end{array}$ \\
\hline FG5 & 5 fathers & $14-19$ & $\begin{array}{l}2 \text { Crohn's disease } \\
1 \text { ulcerative colitis } \\
1 \text { movement disorder } \\
1 \text { muscular dystrophy }\end{array}$ \\
\hline
\end{tabular}

pre-define autonomy, but let parents interpret the level of autonomy of their child relative to their experience.

\section{Data analysis}

The recordings were anonymously transcribed verbatim. Transcripts were read several times and coded according to a thematic analysis process, which implies extracting themes from participants' discourse according to the Grounded Theory process [24]. We attempted to stick as closely as possible to the insights and perceptions of those involved with the subject of interest [20, 21]. Similar coded quotes were then grouped in wider categories and analysed to determine the elements relevant to the research questions. Analyses were done by the first author, systematically examined by the second and discussed between the two in case of discrepancy until reaching consensus. The main author translated into English quotations used in this text.

\section{Results}

Analyses suggested four major categories of preoccupations: autonomy acquisition, giving or taking on autonomy, shared management of treatment and child's future. For some aspects, these implied differences between mothers' and fathers' viewpoints and ways of experiencing this period of life.

\section{Autonomy acquisition}

Differences emerged between mothers and fathers in preoccupations and ways to deal with their child's autonomy acquisition. 
Fathers and mothers put equal emphasis on the fact that mothers were much more 'behind' their child, controlling what s/he was doing:

[His psychiatrist] always tells me "you are always too stuck together, we can never separate you"... and it's true, my husband and my son, they manage to have a good relationship...whereas we are too much in fusion... (Mother 17-year-old male).

In contrast, fathers were said to let go much more and let the child make his/her own mistakes:

My wife is always behind him, stimulating him. And I'm more the opposite; I say to myself, he needs to be late once so he understands that he's wrong, that he needs to pull himself together to get organized in order to make it. [...] I just think that sometimes he needs to fall so that he can learn how to get up alone. (Father 17-year-old male).

Both groups of fathers described mothers as being much more connected and involved in their child's CI, whether physically (working part-time, being more present during consultations etc.) or emotionally (suffering the most from their child's CI) than they were. On the contrary, fathers were described as playing down the importance of certain situations linked to the condition:

The CI weighs a lot on the family. That's why there is a need-as we [fathers] are a little disconnected from the family as such because we are at work all day and we come home in the evening - to cheer up and to bring back, even if it is very artificial, a little optimism in the midst of the bad news. (Father 19-year-old male).

However, although fathers acknowledged that it was mainly the mothers who managed their child's regular treatment, they also insisted on wanting to be present for important medical appointments or interventions:

I tried to be present during all the important checkups, such as the MRIs, one scan a year.
[...] We always try to be two to see the orthopedist, the neurosurgeons, the neuropediatricians [...] We always tried to be together for all these things. (Father 15-year-old male).

Despite their reported lesser day-to-day involvement in their child's CI, fathers described a common dilemma they constantly faced: how much to let go while remaining alert and helpful, and guiding their child through life. They used the metaphor of letting the cord get longer but still holding on to it. Two examples of this dilemma out of many given by fathers illustrate the numerous situations they confronted: a 15-year-old son wanted to close the door of his room at night but his father was worried to miss a likely epileptic crisis; another father lets his 17-year-old daughter sleep at friends' houses, but he is always on his guard and on call in case of an emergency. The father of a 16-year old summarized the situation like this:

I think that it's mainly a question of evaluating the situation and deciding when it can be educational, meaning when to trust him, giving him the possibility to manage everything while supervising at the same time. [...] It's a complicated age because it's an age where we can't treat him like a child and we can't treat him like an adult. (Father 16-year-old male).

\section{Giving and taking on autonomy}

Concerning the processes of giving and taking on autonomy, while no differences appeared between mothers and fathers, disparities appeared between parents and children: either the child having more trouble taking on autonomy or the parents, or both. Overall, parents-whether fathers or mothersregularly confronted three types of situations.

In the first type of situation, it was harder for the parents than for the child to let go: 'It's more difficult for us to let go and to say to ourselves, ok, nothing bad is going to happen'. (Father 15-yearold male). Mothers explained how they were learning to let go and to accept losing control over their child's CI and how it was sometimes difficult: 
Letting go ... [...] I mean, we have to accept the idea that that's how things are and deal with them as well as possible. Accept losing ... not having control. That we never have control...[...] yes, it's a pretty hard transition I think... (Mother 16-year-old male).

In the second type of situation, it was harder for the child than for the parents to let go, according to fathers:

We try not to ask questions because we long for his independence, it's his life... [...] but he is not ready to let go... He is capable of going out and calling us three times to ask us if we are at home! (Father 16-year-old male);

and mothers:

We always have to stimulate him, we always have to encourage him, that's the hardest in daily life... "Go ahead and we'll see, if there's a problem, well, we're here". It's exhausting (Mother 17-year-old male).

In the third type of situation, it was as hard for the parents as for the adolescent to let go. Mothers were trying to push their child forward, towards greater autonomy, sometimes having to force themselves as parents to let go. For instance, one mother chose to work more to be less present at home which forced her child to take on responsibilities and her not to mix in:

I stand firm. I say no, I'm working, that's it. Now she understood that I was working more than before so when she takes her appointments, I'm working, so I tell her 'I'm working, you made your appointment, so you go alone and that's how it is'. [.. .] It's a way to tell her: go ahead. (Mother 17-year-old female).

\section{Shared management of treatment}

Both mothers and fathers depicted varying degrees of autonomy in the ways their children handled their medical treatment and how parents reacted. Moreover, differences between mothers and fathers appeared: while mothers worried about whether to push their children, fathers expressed clear worries concerning their health.

Some mothers tried to persuade their children to become independent with their treatments while understanding the difficulties this generated:

I let her go little by little and say to myself now she is approaching adulthood, she needs to start managing things on her own and to be independent, therefore to make her decisions by herself. But she is going a little the other way, [...] she still wants to be mothered, but I don't think it's good to continue mothering her for years, she is going to have to learn... but it's true that it's not easy to handle all her treatments. (Mother 17-yearold female).

Others reported not trying to push their children because they felt they were not ready yet: 'If I would tell her now that it's finished, you make your own way, she would totally panic!' (Mother 16-year-old female). And for others, parents could not interfere anymore as children wanted to be completely autonomous:

Everything to do with taking medication [...] she manages by herself. And if I don't interfere with that, she talks about it. But if I make one sign that I am interfering then ... it's very violent. In other words, she gets mad and that's it...so...I don't ask whether or not she took it [her medication]. (Mother 15 -year-old female).

These differences appeared to correspond less to a child's age than to parent and adolescent personalities.

Similarly, fathers' perspectives on medication handling also demonstrated very different degrees of autonomy among their children that were not necessarily linked to age. Some considered their children completely autonomous:

Given his self-confidence and the fact that he understood things well, [...] I didn't feel anxious. He understood so well how to manage 
The needs of chronically ill adolescents' parents

himself that it was okay. [...] he understood why he had to inject insulin, why he had to eat at certain hours, how much he should eat... (Father 16-year-old male).

Whereas others considered their children to be completely dependent on their parents, having to constantly push them forward: 'Concerning medication intake, it's a disaster. [...] We absolutely need to be there otherwise he... [doesn't take it][...] We are really obliged to follow him ...' (Father 14-year-old male).

Fathers who believed their children lacked autonomy expressed frequent worry concerning medication intake. For instance, one mentioned concerns linked to the ambiguity between his child wanting to be autonomous but not handling it completely on her own:

If we ask her "did you take your medication?" or "Do you have enough until the next medical visit?" it can quickly become electric [she will answer]: "I know, I'm taking care of it". But sometimes, suddenly she'll say "I don't have anymore!!" So we quickly have to run to the hospital pharmacy to pick up what we need. (Father 17-year-old female).

Anxiety was also felt by fathers who constantly worried about whether their children took the required medication, especially when away from home:

Medication, it's twice a day, morning and evening, so we are always worried, wondering if he took it or if he didn't take it... If he's away, if he has medication with him, that kind of everyday challenge is a constant source of worry. (Father 15-year-old male).

Others expressed concern about their children not wanting to let anyone else know about their illness:

My main worry concerns his discretion; he doesn't want to bother others with his diabetes. [...] So he wants to do his treatment fast so he can be with the others. That makes me a little worried that he doesn't disinfect himself before the injection, that he miscalculates his dose... (Father 16-year-old male).

\section{Child's future}

Gender differences emerged concerning the future autonomy of adolescents with CI as mothers expressed frequent concern regarding their professional lives, whereas fathers focused more on their future health. Similarities also appeared between mothers and fathers as both articulated worries concerning their children acquiring social skills.

Mothers expressed many worries concerning their children's future professional lives: 'The question of professional life comes up dramatically and acutely' (Mother 16-year-old male) particularly when taking into account the specificities of their CI:

Well, now there is the choice of the profession that is coming up because this year he is going to have to choose an option and he has to choose it based on his abilities, his possibilities, therefore according to his degree of autonomy ... (Mother 16-year-old male).

Mothers also suggested that the CI became more of a problem when reaching the 'adult world' precisely because of the difficulties in finding an apprenticeship or a job that corresponds to the physical limitations resulting from the $\mathrm{CI}$, when compared with the protected school environment:

He wanted to be a carpenter but he doesn't have enough strength and when he is standing still, he has hip pain [...], so woodcarver we can forget, carpenter we can forget, afterwards he did lots and lots of internships to see if his physical state was adequate for the job ... (Mother 17-year-old male).

An important preoccupation expressed by mothers was how to handle the discrepancies between their children's plans and desires for the future and what they know, or think they know, to be realistic in terms of their often limited capacities. The questions raised were whether parents should explain the limits or let their children discover them on their own; and if explained, when and how it should be done:

My daughter wants to enter the police school. And the problem is that she has this arthritis 
[...]. And entrance to this school presupposes many physical tests ... so how is she going to manage? Will she manage? Should we stop her now [...] or should we leave everything open? That is nerve-racking because, as parents, we don't know where to stop and say: "Listen, why don't you choose another path", [...] it's very difficult to manage such a situation. (Mother 17-year-old female).

Finally, contrary to mothers, fathers were said to be quite confident in the future professional life of their children. Their worries were more focused on the future health of their children in terms of physical consequences of today's mistakes (diabetes):

I'm worried about when he will be 50 years old. I wonder what state he will be in: eyes, kidneys, things like that... [...] He needs to understand that today's mistakes or inattentions will have consequences later on. And I'm not sure he has understood that. (Father 16-year-old male).

\section{Discussion}

Our study highlights the challenges parents face on the road to autonomy for their adolescent children with CI. In particular, it suggests two main findings. First, parents have difficulties striking a balance between controlling, letting go and everything else on the spectrum between the two such as trusting and guiding. Second, there are several key differences in the way mothers and fathers of adolescents with CI react.

Mothers and fathers dealt in different ways with their child's search for autonomy, as they were concerned about different aspects of their child's life. For instance, mothers were particularly preoccupied with professional aspects, while fathers were more concerned with health in the long run. Parents seemed to need help in these areas and this type of discussion between adolescent, parents and health professionals can relieve both mothers and fathers regarding their adolescent child's future.
Additionally, mothers were seen to be more present and in charge of the adolescent with CI when compared with fathers who preferred letting them make their own mistakes. This can be explained by the fact that mothers mostly worked part time, therefore more available to take care of their children, as well as by overall socially gendered norms of what mothering and fathering implies. However, despite fathers being more absent on a daily basis, they insisted on being present at important medical meetings. Health professionals should take this wish into account by inviting fathers to significant medical appointments.

Furthermore, fathers reported complementing mothers' reactions by consciously taking part in playing down dramatic situations where mothers become emotional. These findings are consistent with those of Swallow et al. [25] who described parents' role divergence when dealing with large amounts of information provided by professionals: mothers tend to become emotional whereas fathers tend to be calmer.

In our study, parents accounted for very different degrees of autonomy among their children in terms of handling their medical treatment. Those who reported having adolescent children with low levels of autonomy felt under considerable distress. Low levels of autonomy in this area could be due to lack of therapeutic education [26]. However, our results show that autonomy is not necessarily linked to age; and in the pediatric clinics of our university hospital, adolescents generally learn how to handle their treatments through therapeutic education before age 16 . Therefore, medication handling seems to be more a matter of acquiring autonomy and relations with parents than treatment management know-how. Consequently, in line with Kieckhefer et al. [27] health professionals should provide support in parent-child shared management implying as much autonomy as possible. Their inquiries in this connection should be made independently of child's age.

While health professionals generally focus their attention on the adolescent patient, parents of adolescents with CI are often left aside and ill prepared for their child's transition. However, as chronically ill children grow up, parents need backing so they 
can optimally support their children's growing autonomy while they are in a constant balance between wanting to be involved and wanting their child to manage on his/her own. As front-line educators, parents play an essential role, and the child-parent relationship has a critical influence on the child's ability to manage illness [28]. Even the more so, the relationship adolescents with CI have with their parents is crucial and some studies suggest that the need for parental support can actually increase in young adulthood $[29,30]$. For instance, in the case of diabetes care, there is growing evidence showing that psycho-social interventions aiming at improving outcomes are more effective when including continued parental involvement [31]. Following Meah et al.'s [10] and Williams et al.'s [8] conclusions and knowing that there is good evidence for the effectiveness of problem solving therapy delivered to parents [32], it appears essential to better acknowledge and respond to the needs of these parents by offering them psychosocial interventions.

Previous research has reported on family functioning [33], quality of parent-adolescent relationship [34], and parents' experiences with their role as caregivers for adolescents with CI [25, 35]. However, to our knowledge, this is the first study taking into account fathers' and mothers' perspectives regarding autonomy acquisition using a noncategorical approach.

\section{Conclusion}

Both parents and adolescents stand to gain from health professionals who take into account the differences in perspective between mothers and fathers concerning the process of autonomy. Letting go can be hard for the father, the mother, the adolescent or all three of them. Helping one or the other can in turn improve family functioning as a whole. Reported findings may help health professionals better assist parents in managing and coping with their child's acquisition of autonomy.

Future interventions focusing on parents of adolescents with CI need to be undertaken to provide them with tools to help them let go while guiding their children on the road to autonomy. Future interventions should also assess whether parents could benefit from peer-to-peer support and education as they navigate and support the needed autonomy development of their adolescent. Interactive interventions would allow including parents' personal experiences in proposed solutions. Finally, mothers as well as fathers should be integrated as they do not always have the same needs.

\section{Acknowledgements}

We thank all focus group participants as well as J.-M. Chabloz and C. Lecygne for their help in running the focus groups. We also thank Dr G. Hafen, Dr M. Hauschild, Dr M. Hofer, Dr C. Newman, Dr A. Nydegger, and Dr I. Rochat for their collaboration.

\section{Conflict of interest statement}

None declared.

\section{References}

1. Pardeck JA, Pardeck JT. Family factors related to adolescent autonomy. Adolescence 1990; 25: 311-9.

2. Small SA, Eastman G, Cornelius S. Adolescent autonomy and parental stress. J Youth Adolesc 1988; 17: 377-91.

3. Suris JC, Michaud PA, Viner R. The adolescent with a chronic condition. Part I: developmental issues. Arch Dis Child 2004; 89: 938-42.

4. Michaud PA, Suris JC, Viner R. The adolescent with a chronic condition. Part II: healthcare provision. Arch Dis Child 2004; 89: 943-9.

5. Holmbeck GN, Johnson SZ, Wills KE et al. Observed and perceived parental overprotection in relation to psychosocial adjustment in preadolescents with a physical disability: the mediational role of behavioral autonomy. J Consult Clin Psychol 2002; 70: 96-110.

6. Power TG, Dahlquist LM, Thompson SM et al. Interactions between children with juvenile rheumatoid arthritis and their mothers. J Pediatr Psychol 2003; 28: 213-21.

7. Leblanc LA, Goldsmith T, Patel DR. Behavioral aspects of chronic illness in children and adolescents. Pediatr Clin North Am 2003; 50: 859-78.

8. Williams B, Mukhopadhyay S, Dowell J et al. Coyle J. From child to adult: an exploration of shifting family roles and responsibilities in managing physiotherapy for cystic fibrosis. Soc Sci Med 2007; 65: 2135-46. 
9. Patterson J, Blum RW. Risk and resilience among children and youth with disabilities. Arch Pediatr Adolesc Med 1996; 150: $692-8$.

10. Meah A, Callery P, Milnes L et al. Thinking 'taller': sharing responsibility in the everyday lives of children with asthma. J Clin Nurs 2010; 19: 1952-9.

11. Trachtenberg SW, Batshaw K, Batshaw M. Caring and coping: helping the family of a child with a disability. In: Batshaw ML, Pellegrino L, Roizen NJ (eds). Children with Disabilities, 6th edn. Baltimore, MD: Brookes Publishing, 2007, 792.

12. Churchill SS, Villareale NL, Monaghan TA et al. Parents of children with special health care needs who have better coping skills have fewer depressive symptoms. Mat Child Health J 2010; 14: 47-57.

13. Bourdeau TL, Mullins LL, Carpentier MY et al. An examination of parenting variables and child self-care behavior across disease groups. J Dev Phys Disabil 2007; 19: 125-34.

14. Giarelli E, Bernhardt BA, Mack R et al. Adolescents' transition to self-management of a chronic genetic disorder. Qual Health Res 2008; 18: 441-57.

15. Newbould J, Smith F, Francis SA. 'I'm fine doing it on my own': partnerships between young people and their parents in the management of medication for asthma and diabetes. J Child Health Care 2008; 12: 116-28.

16. Allen D, Gregory J. The transition from children's to adult diabetes services: understanding the 'problem'. Diab Med 2009; 26: 162-6.

17. Ribi K, Landolt MA, Vollrath M. Fathers of children with chronic illnesses. Prax Kinderpsychol Kinderpsychiatr 2002; 51: $357-72$.

18. Goldstein H, Akre C, Belanger RE et al. Detached, distraught or discerning? Fathers of adolescents with chronic illness: a review of the literature. Int J Adolesc Med Health 2013; 25: 109-17.

19. Rich M, Ginsburg KR. The reason and rhyme of qualitative research: why, when, and how to use qualitative methods in the study of adolescent health. J Adolesc Health 1999; 25: 371-8.

20. Kitzinger J. Qualitative research. Introducing focus groups. BMJ 1995; 311: 299-302.

21. Morgan DL. Focus groups. Annl Rev Socio. 1996; 22: 129-52.

22. Vermeire E, Van Royen P, Griffiths F et al. The critical appraisal of focus group research articles. Eur J Gen Pract 2002; 8: 104-8.
23. Perrin EC, Newacheck P, Pless IB et al. Issues involved in the definition and classification of chronic health conditions. Pediatrics 1993; 91: 787-93.

24. Collingridge DS, Gantt EE. The quality of qualitative research. Am J Med Qual 2008; 23: 389-95.

25. Swallow V, Lambert H, Santacroce S et al. Fathers and mothers developing skills in managing children's longterm medical conditions: how do their qualitative accounts compare? Child Care Health Dev 2011; 37: 512-23.

26. Kelo M, Martikainen M, Eriksson E. Self-care of school-age children with diabetes: an integrative review. $J$ Adv Nurs 2011; 67: 2096-108.

27. Kieckhefer GM, Trahms CM, Churchill SS et al. Measuring parent-child shared management of chronic illness. Pediatr Nurs 2009; 35: 101-8, 27.

28. Miller-Johnson S., Emery RE, Marvin RS et al. Parent-child relationships and the management of insulin-dependent diabetes mellitus. J Consult Clinic Psychol 1994; 62: 603-10.

29. Gillies V, Ribbens McCarthy J, Holland J. Pulling together, pulling apart: the family lives of young people. York: Family Policy Studies Centre, 2001.

30. Jones K, Hammersley S, Shepherd M. Meeting the needs of young people with diabetes: an ongoing challenge. J Diabetes Nursing 2003; 7: 345-50.

31. Murphy HR, Wadham C, Rayman G et al. Approaches to integrating paediatric diabetes care and structured education: experiences from the Families, Adolescents, and Children's Teamwork Study (FACTS). Diabetic Med 2007; 24: 1261-8.

32. Eccleston C, Palermo TM, de C, Williams AC et al. Psychological therapies for the management of chronic and recurrent pain in children and adolescents. Cochrane Database Syst Rev 2012; 12: CD003968.

33. Gerhardt CA, Vannatta K, McKellop JM et al. Comparing parental distress, family functioning, and the role of social support for caregivers with and without a child with juvenile rheumatoid arthritis. J Pediatr Psychol 2003; 28: 5-15.

34. Berg CA, King PS, Butler JM et al. Parental involvement and adolescents' diabetes management: the mediating role of self-efficacy and externalizing and internalizing behaviors. J Pediatr Psychol 2011; 36: 329-39.

35. Helgeson VS, Reynolds KA, Siminerio L et al. Parent and adolescent distribution of responsibility for diabetes selfcare: links to health outcomes. J Pediatr Psychol 2008; 33: 497-508. 